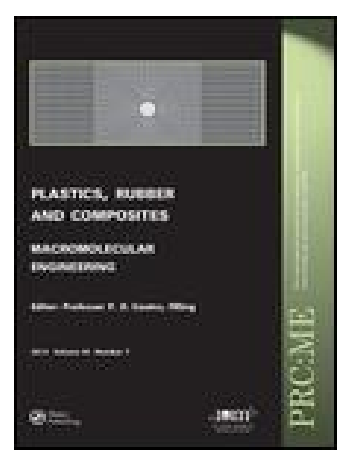

Plastics, Rubber and Composites

Macromolecular Engineering

ISSN: 1465-8011 (Print) 1743-2898 (Online) Journal homepage: http://www.tandfonline.com/loi/yprc20

\title{
Studies on thermal-oxidative degradation behaviours of raw natural rubber: PRI and thermogravimetry analysis
}

\section{P Danielle Galiani, J Antonio Malmonge, B Guenther Soares \& L Henrique Capparelli Mattoso}

To cite this article: P Danielle Galiani, J Antonio Malmonge, B Guenther Soares \& L Henrique Capparelli Mattoso (2013) Studies on thermal-oxidative degradation behaviours of raw natural rubber: PRI and thermogravimetry analysis, Plastics, Rubber and Composites, 42:8, 334-339, DOI: 10.1179/1743289811Y.0000000046

To link to this article: https://doi.org/10.1179/1743289811Y.0000000046

曲 Published online: 03 Dec 2013.

Submit your article to this journal $₫$

Џلll Article views: 108

4 Citing articles: 1 View citing articles 준 


\title{
Studies on thermal-oxidative degradation behaviours of raw natural rubber: PRI and thermogravimetry analysis
}

\author{
P. Danielle Galiani*1 ${ }^{1}$, J. Antonio Malmonge ${ }^{2}$, B. Guenther Soares ${ }^{1}$ and \\ L. Henrique Capparelli Mattoso ${ }^{3}$
}

Thermal-oxidative degradation behaviours of raw natural rubber (NR) have been investigated by using thermogravimetry analysis in inert and oxidative atmospheres and the plasticity retention index (PRI). The activation energy $E_{\mathrm{a}}$, was calculated using Horowitz-Metzger and Coats-Redfern methods and compared with PRI. The $E_{\mathrm{a}}$ values obtained by each method were in good agreement with each other. The June samples are the least stable rubbers among the studied ones, whereas February samples exhibited the highest values of activation energy, therefore in agreement with the PRI behaviour, which indicates that the thermo-oxidative stability of the June samples are the poorest during the thermo-oxidative degradation reaction. Natural rubber is a product of biological origin, and thus these variations in the values of thermal behaviour and PRI might be related to the genetic differences and alterations of climatic conditions that act directly on the synthesis of non-rubber constituents, which are generally reflected in latex and rubber properties.

Keywords: Natural rubber, Thermogravimetry analysis, PRI, Degradation

\section{Introduction}

Natural rubber (NR) is used in $>40000$ consumer products, including $>400$ medical devices, due to its unique properties, which include resilience, elasticity, abrasion and impact resistance, efficient heat dispersion, and malleability at cold temperatures. ${ }^{1}$ The sole commercial source, at present, is NR harvested from the Brazilian rubber tree, Hevea brasiliensis. ${ }^{2}$ About $10 \%$ of the latex harvested from Hevea trees is manufactured into latex products. The remaining $90 \%$ of latex is coagulated and converted into dry rubber. Most of the dry NR is used in tires, especially those which call for high performance, notably aircraft and truck tires.

Natural rubber is susceptible to oxidation, which may affect both the processing qualities of the rubber and also the final compounded rubber mechanical properties. The quality of a rubber manufactured product depends on the raw rubber quality. It is known that several factors influence the NR physical-chemicals properties; moreover, industries are increasingly demanding for quality and uniformity of the NR produced in the country. The

\footnotetext{
${ }^{1}$ Institute of Macromolecules (IMA), Federal University of Rio de Janeiro (UFRJ), Av. Horácio Macedo, 2·030, BI. J-21941-598, Rio de Janeiro, RJ State, Brazil

${ }^{2}$ Department of Physics and Chemistry, São Paulo State University (UNESP), Av. Brasil, 56-15385-000, Ilha Solteira, SP State, Brazil

${ }^{3}$ Embrapa Agricultural Instrumentation (CNPDIA), Rua XV de Novembro, 1452-13560-970, São Carlos, SP State, Brazil

*Corresponding author, email patrinigaliani@yahoo.com.br
}

plasticity retention index (PRI) is a measure which reflects the resistance of NR to thermal oxidation. ${ }^{3}$ This index is a property widely used by manufacturers, mainly tire industry that is the major NR user. The parameters required by Brazilian Standard NBR $11597^{4}$ specify $60 \%$ as the minimum acceptable value for all rubber categories.

Knowledge of degradation and mode of decomposition under the influence of heat is highly recommendable in the processing and fabrication procedures. ${ }^{5}$ Thermogravimetric analysis (TGA) has proved to be a highly successful technique for determining the thermal stability of polymeric systems. Thermal stability can be regarded as the ability to maintain the required properties of materials at a desired temperature. To study how the decomposition temperature is related to the structure of materials, TGA is widely used to determine the range of service temperature due to its simplicity to analyse the information obtained from a simple thermogram. ${ }^{6}$ Because thermal stability is related to both the initial degradation temperature and the degradation rate of a polymer, the determination of activation energy is very important. $^{7,8}$

Degradation and stabilisation of polymers have been studied from both fundamental and practical points of view for a long time. ${ }^{9}$ The derivation of kinetic data in the study of polymer decomposition has received increasing attention in the last decade. Flynn-Wall-Ozawa, Horowitz-Metzger and Coats-Redfern methods are commonly used to determine the kinetic parameters as activation energy. ${ }^{10-16}$

In this paper, the thermal-oxidative degradation of raw NR samples collected in February and June, from 
GT1 and PR255 clones, has been studied in detail by TGA under oxidative and inert atmospheres. The purpose is to evaluate the thermal and thermo-oxidative degradation behaviours and compare to the PRI (\%) data for each clone. The kinetic parameter (activation energy $E_{\mathrm{a}}$ ) was calculated using two relations: Horowitz-Metzger and Coats-Redfern.

\section{Experimental}

Material

\section{Natural rubber}

Natural rubber (Hevea brasiliensis) lattices from GT1 and PR255 clones were collected from different trees, in summer (February) and winter (June), in the region of Mato Grosso State, Brazil. These clones were chosen to represent good clones available in Brazil. The trees were planted in 1989 (i.e. they were 19 years old at the beginning of the experiment). The samples were prepared in a rubber processing factory. In order to obtained dry rubber, all cup lumps were then granulated, washed and dried in an air dryer at $120 \pm 2^{\circ} \mathrm{C}$ for $4 \mathrm{~h}$ under the same processing conditions to avoid between-batch variations.

\section{Methods}

\section{Plasticity retention index}

Plasticity retention index analysis ${ }^{17}$ consists of determining the Wallace plasticity $P_{0}$ of a standardized NR specimen (thickness $3-3.8 \mathrm{~mm}$ ) before and after $30 \mathrm{~min}$ aging at $140^{\circ} \mathrm{C}$, in an oven with controlled air circulation. The PRI, percentage of Wallace plasticity retained, is then given by equation (1)

$$
\mathrm{PRI}=\frac{P_{30}}{P_{0}} \times 100
$$

where $P_{30}$ is the plasticity after aging in the oven, and $P_{0}$ is the plasticity before aging in the oven.

\section{Thermogravimetric analysis}

The thermal degradation parameters of rubber samples from GT1 and PR 255 clones were evaluated using the TA instrument thermoanalyser Q500, and thermogravimetric (TG) scans were carried out with $10 \pm 1 \mathrm{mg}$ of the samples in platinum pans, heated from room temperature up to $600^{\circ} \mathrm{C}$ at a rate of $10^{\circ} \mathrm{C} \mathrm{min}{ }^{-1}$ in oxidative and inert atmospheres with a flow rate of $40 \mathrm{~mL} \mathrm{~min}^{-1}$. The TG curves were analysed as percentage weight loss as a function of temperature. The decomposition stages were identified using a derivative of the TG curves. Several methods have been developed in order to investigate the thermal stability of rubbers. ${ }^{18}$ The kinetic parameters evaluated for each stage of degradation processes are carried out by using the integral methods for the kinetic analysis of the single thermogravimetric curve data. Several approaches have been proposed in literature for the integral of the Arrhenius equation in order to determine the activation energy from experimental integer data. ${ }^{19}$

In this paper, the activation energy for decomposition $E_{\mathrm{a}}$ has been calculated from the slopes of the best fit straight lines obtained when the plots using two models, namely, Horowitz-Metzger ${ }^{20}$ and Coats-Redfern ${ }^{21}$ methods, which are the most acceptable and commonly are used to obtain kinetic data., 14,16,19,22 Nevertheless, there are still some doubts about their accuracy for determining the kinetic parameters ${ }^{19}$ because their lack of accuracy in the estimation of the temperature integral. However, the most common application of these approximations is the determination of the activation energy and not the computation of the temperature integral. ${ }^{19}$

Table 1 presents the relation used to evaluate the degradation kinetics for each model.

\section{Results and discussion}

The thermal decomposition temperatures of the polymers were evaluated by TGA and derivative thermogravimetric (DTG) analysis in inert and oxidative atmospheres. Additionally, there is a significant dependence on the thermal decomposition of NR samples under the test atmosphere, as can be seen in Figs. 1 and 2. The mean features of the thermograms are characterised by a decrease in the maximum degradation temperature $\left(\sim 30^{\circ} \mathrm{C}\right)$ observed in the thermograms obtained for both clones under the oxidative atmosphere.

The decomposition stages were identified using a derivative of the TG curves, and thus, Tables 2 and 3 show the maximum temperature of each stage of degradation and the percentage of loss mass in oxidative atmosphere for GT1 and PR255 clones respectively.

Natural rubber has a chemical structure [poly $($ cis-1,4isoprene)], based around a double bond building unit that makes it susceptible to oxidation, which can be caused by light, high temperatures, atmospheric oxidants $\left(\mathrm{O}_{2}, \mathrm{O}_{3}\right.$, etc. $)$ or excessive physical stresses. ${ }^{17}$ Thermal oxidation of this polymer, in its solid state, is a complex process in which two competing phenomena occur: scission and cross-linking, resulting in the

Table 1 Relation used for each model*

\begin{tabular}{|c|c|c|c|}
\hline Model & Equation & & Where \\
\hline $\begin{array}{l}\text { Horowitz- } \\
\text { Metzger }\end{array}$ & $\log \left[\frac{-\log (1-\alpha)}{T^{2}}\right]=\log \frac{A R}{\beta E}\left[1-\frac{2 R T}{E_{a}}\right]$ & $-\frac{E_{a}}{2.303 R T}$ & $\begin{array}{l}\alpha \text { is the decomposed fraction, } \\
E_{\mathrm{a}} \text { is the activation energy of decomposition, } \\
T_{\mathrm{m}} \text { is the temperature at the maximum rate of } \\
\text { weight loss, } \theta \text { is the value of } T-T_{\mathrm{m}} \text { and } R \text { is the } \\
\text { gas constant. From the plots of } \log [-\log (1-\alpha)] \\
\text { versus } \theta \text {, the activation energy } E_{\mathrm{a}} \text { for decomposition } \\
\text { can be determined from the slope of the straight line of the plots. } \\
\alpha \text { is the fraction of sample decomposed at the time } \\
T, T \text { is the derivative peak temperature, } A \text { is the } \\
\text { frequency factor, } E_{\mathrm{a}} \text { is the activation energy and } \\
R \text { is the gas constant. A plot of log }\left[-\log (1-\alpha) / T^{2}\right] \\
\text { versus } 1 / T \text { gives the slope for evaluation of the activation } \\
\text { energy most appropriately, for } n=1 .\end{array}$ \\
\hline
\end{tabular}

*For solid state reactions $f(\alpha)=(1-\alpha)^{n}$, where $n$ is the order of reaction, for many pyrolysis processes, $n=1$, i.e. first order reaction. ${ }^{22}$ 

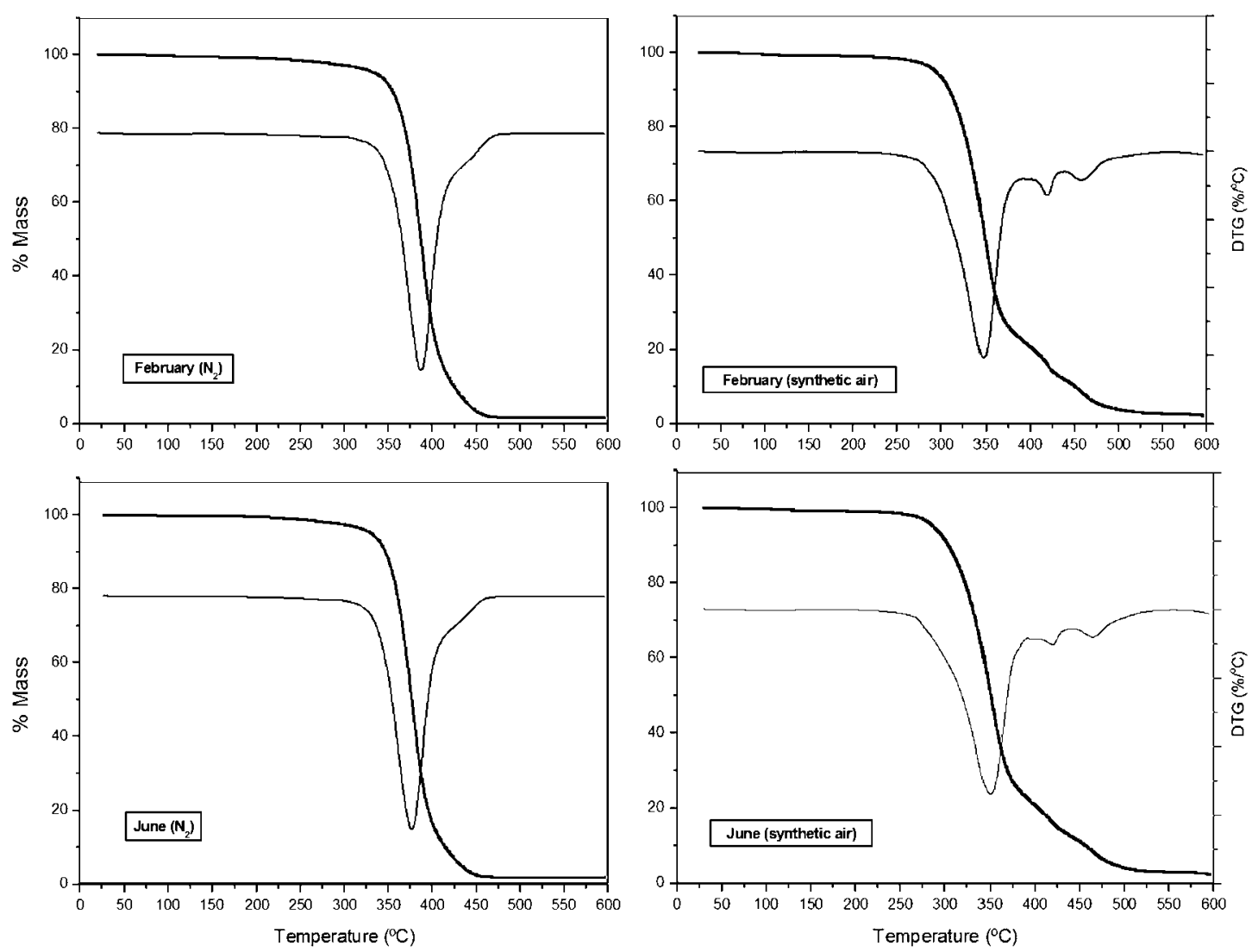

1 Curves (TG/DTG) of NR samples collected in February and June from GT1 clone heated from room temperature to $600^{\circ} \mathrm{C}$ at rate of $10^{\circ} \mathrm{C} \mathrm{min}^{-1}$, under nitrogen and oxidative (synthetic air) atmosphere

deterioration of the chemical and physical properties. ${ }^{23}$ According to Tangpakdee and Tanaka, ${ }^{24}$ variations in these properties occur due to a larger or smaller quantity of non-rubber constituents that will influence rubber characteristics, such as, for instance, in the formation of cross-linking, and molecular mass variations and its distribution.

GT1 and PR255 clones showed similar decomposition behaviour in inert atmosphere (Figs. 1 and 2 respectively), indicating that thermal degradation of the raw NR from the GT1 and PR255 clones is mostly a one stage process. The decomposition ranged from $\sim 315$ to $450^{\circ} \mathrm{C}$ with a mass loss of $\sim 96 \%$, which can be assigned to the thermal decomposition of the NR into monomers, dimers, trimers, etc. A small shoulder can be observed at $\sim 430^{\circ} \mathrm{C}$ attributed to the cross-linked and cyclized networks, which degrade at a higher temperature. $^{25}$

For the oxidative atmosphere, the nature of TG curves indicates that the rubber samples degrade in three stages, except for the sample collected in February from PR255 clone (Fig. 2), which show two stages of degradation. The results showed that degradation did not occur in a single stage, and around the main peak there are some small peaks. These peaks could not be separated completely, but overlap each other, indicating that the degradation consists of several reactions. ${ }^{26}$ The occurrence of two or more peaks in the thermogram indicates the formation of thermally stable intermediate products: ${ }^{25,27}$ this behaviour is an evidence of the multiple stage degradation that occurs in NR. ${ }^{28}$ Li et $a l .{ }^{29}$ reported that the thermal degradation of NR in air is not a simple random chain scission process, but also has some side reactions that are carried out simultaneously. In addition, the process of degradation is an exothermic reaction.

From the results in Table 2, it can be seen that the first stage ranges from 265 to $395^{\circ} \mathrm{C}$ and the second one ranges from 395 to $438^{\circ} \mathrm{C}$. The third decomposition process, appearing at the highest temperatures, ranges from 439 to $493^{\circ} \mathrm{C}$. For PR255 clone (Table 3), the scans illustrate that thermal degradation of the rubber samples presented the first stage ranges from 271 to $398^{\circ} \mathrm{C}$ and the second one ranges from 384 to $517^{\circ} \mathrm{C}$. The third decomposition process ranges from 432 to $521^{\circ} \mathrm{C}$, appearing only for the sample collected in June.

The first stage of degradation of the rubber samples started at $\sim 260^{\circ} \mathrm{C}$ and was completed at $400^{\circ} \mathrm{C}$, and the mass loss is $\sim 50 \%$, which can be attributed to the thermal decomposition of the NR. At these temperatures, the main reaction was an oxidative degradation, accompanied by the occurrence of mass loss, which is more time dependent and intense as temperature increases than it normally occurs for experiments carried out under nitrogen atmosphere. ${ }^{25,29,30}$ The second mass loss peak, between 80 and $94 \%$, temperature up to $385^{\circ} \mathrm{C}$ can be attributed to the final thermal decomposition of the NR. For the third mass loss peak, the mass loss is $\sim 95 \%$, and it ranges from $\sim 430$ to $600^{\circ} \mathrm{C}$, associated with the thermal decomposition of the carbonaceous residues from the rubber. During the propagation stage, polymer radicals formed by chain scission combine with oxygen to yield peroxy radicals. Moreover, the oxidation process may be accelerated by further decomposition of the hydroperoxides to generate free radicals. $^{28,31}$ 

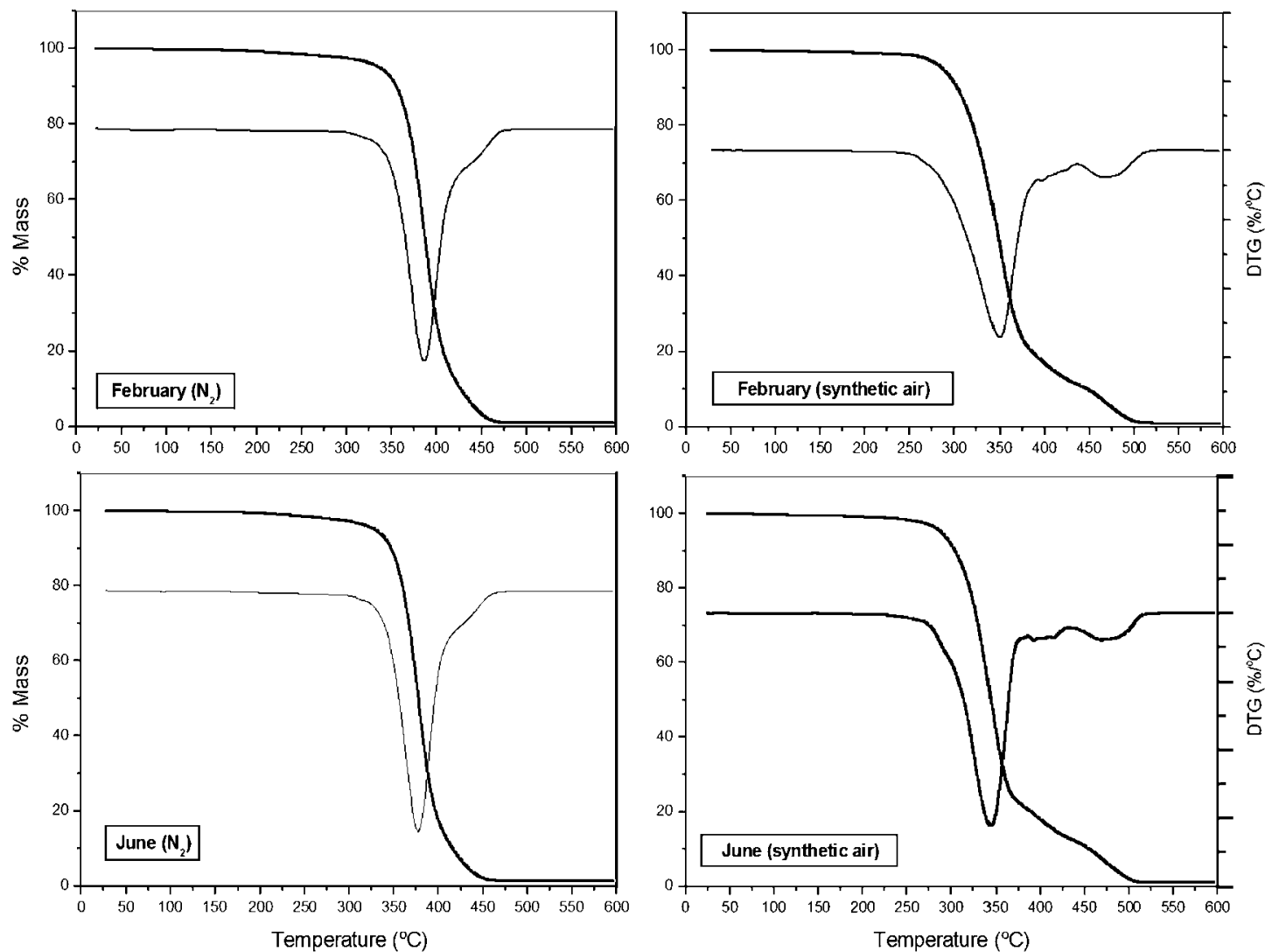

2 Curves TG/DTG of NR samples collected in February and June from PR255 clone heated from room temperature to $600^{\circ} \mathrm{C}$ at rate of $10^{\circ} \mathrm{C} \mathrm{min}^{-1}$, under nitrogen and oxidative (synthetic air) atmosphere

Further information on the thermal degradation of the rubber samples were obtained from the kinetic parameter (activation energy $E_{\mathrm{a}}$ ) calculated by the HorowitzMetzger and Coats-Redfern methods. In this paper the $E_{\mathrm{a}}$ values of the rubber samples in nitrogen were compared with those found in air for each method. The authors also investigated the relationship of the $E_{\mathrm{a}}$ and PRI (resistance to thermal degradation) results among the tappings (February and June) and clonal origin.
The linear dependence of thermal degradation of NR samples as a function of temperature, as per Coats-Redfern and Horowitz-Metzger methods in oxidative and inert atmospheres, was obtained. The linear plot with concurrency value $R^{2}$ around 0.98 was chosen for all methods. The activation energy was calculated by regression analysis and the results obtained in oxidative and inert atmospheres are presented in Figs. 3 and 4 respectively.

Table 2 Maximum degradation temperature $T_{\max }$ for each degradation stage for GT1 clone under oxidant atmosphere and respective mass loss

\begin{tabular}{|c|c|c|c|c|c|c|}
\hline Clone & Stage I & & Stage II & & Stage III & \\
\hline GT1 & $\begin{array}{l}\Delta T /{ }^{\circ} \mathrm{C} \text { and } \\
T_{\text {max }} /{ }^{\circ} \mathrm{C}\end{array}$ & $\begin{array}{l}\text { \%mass } \\
\text { loss in } T_{\max }\end{array}$ & $\begin{array}{l}\Delta T /{ }^{\circ} \mathrm{C} \\
\text { and } T_{\text {max }} /{ }^{\circ} \mathrm{C}\end{array}$ & $\begin{array}{l}\text { \%mass } \\
\text { loss in } T_{\max }\end{array}$ & $\begin{array}{l}\Delta T /{ }^{\circ} \mathrm{C} \text { and } \\
T_{\text {max }} /{ }^{\circ} \mathrm{C}\end{array}$ & $\begin{array}{l}\% \text { mass } \\
\text { loss in } T_{\max }\end{array}$ \\
\hline February & $\begin{array}{l}280-390 \\
347\end{array}$ & $\begin{array}{l}49 \cdot 3 \pm 0.1 \\
\ldots\end{array}$ & $\begin{array}{l}401-438 \\
421\end{array}$ & $\begin{array}{l}84 \cdot 4 \pm 0 \cdot 1 \\
\ldots\end{array}$ & $\begin{array}{l}439-493 \\
458\end{array}$ & $\begin{array}{l}91 \cdot 0 \pm 0 \cdot 1 \\
\ldots\end{array}$ \\
\hline June & $\begin{array}{l}265-395 \\
349\end{array}$ & $\begin{array}{l}50 \cdot 2 \pm 0 \cdot 1 \\
\ldots\end{array}$ & $\begin{array}{l}395-435 \\
420\end{array}$ & $\begin{array}{l}84 \cdot 1 \pm 0 \cdot 1 \\
\ldots\end{array}$ & $\begin{array}{l}448-483 \\
466\end{array}$ & $\begin{array}{l}92 \cdot 2 \pm 0 \cdot 1 \\
\ldots\end{array}$ \\
\hline
\end{tabular}

Table 3 Maximum degradation temperature $T_{\max }$ for each degradation stage for PR255 clone under oxidant atmosphere and respective mass loss

\begin{tabular}{|c|c|c|c|c|c|c|}
\hline Clone & Stage I & & Stage II & & Stage III & \\
\hline PR255 & $\begin{array}{l}\Delta T /{ }^{\circ} \mathrm{C} \\
\text { and } T_{\text {max }} /{ }^{\circ} \mathrm{C}\end{array}$ & $\begin{array}{l}\text { \%mass } \\
\text { loss in } T_{\max }\end{array}$ & $\begin{array}{l}\Delta T /{ }^{\circ} \mathrm{C} \\
\text { and } T_{\text {max }} /{ }^{\circ} \mathrm{C}\end{array}$ & $\begin{array}{l}\text { \%mass } \\
\text { loss in } T_{\max }\end{array}$ & $\begin{array}{l}\Delta T /{ }^{\circ} \mathrm{C} \text { and } \\
T_{\text {max }} /{ }^{\circ} \mathrm{C}\end{array}$ & $\begin{array}{l}\text { \%mass } \\
\text { loss in } T_{\max }\end{array}$ \\
\hline February & $\begin{array}{l}280-398 \\
351\end{array}$ & $52 \cdot 2 \pm 0 \cdot 1$ & $\begin{array}{l}442-517 \\
472\end{array}$ & $94 \cdot 2 \pm 0 \cdot 1$ & $\ldots$ & $\ldots$ \\
\hline June & $\begin{array}{l}271-383 \\
346\end{array}$ & $\begin{array}{l}48 \cdot 3 \pm 0 \cdot 1 \\
\ldots\end{array}$ & $\begin{array}{l}384-430 \\
405\end{array}$ & $\begin{array}{l}83 \cdot 2 \pm 0.1 \\
\ldots\end{array}$ & $\begin{array}{l}432-521 \\
478\end{array}$ & $\begin{array}{l}94 \cdot 4 \pm 0 \cdot 1 \\
\ldots\end{array}$ \\
\hline
\end{tabular}




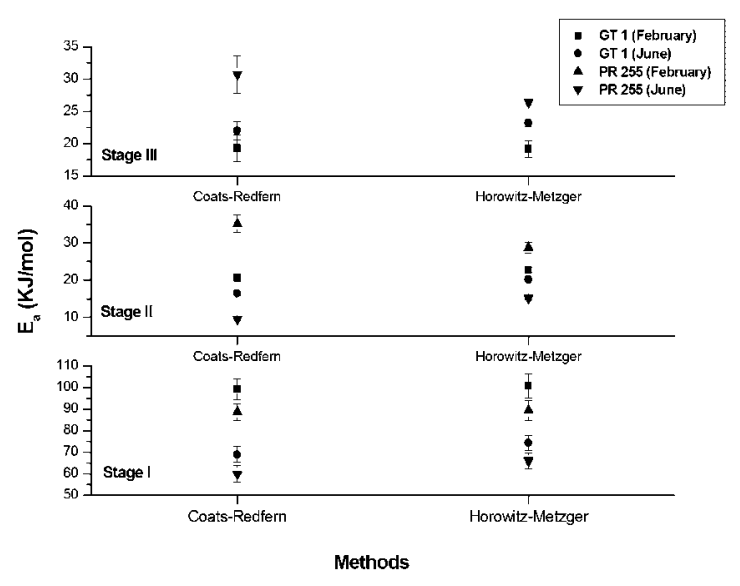

3 Activation energy $E_{a}$ of thermal decomposition curve (in oxidative atmosphere) for NR samples obtained for different methods at different degradation stages

The results obtained by the Coats-Redfern method were in agreement with the results of Horowitz-Metzger method. In the first stage, attributed to the thermal decomposition of the NR, the $E_{\mathrm{a}}$ values varied between 55 and $105 \mathrm{~kJ} \mathrm{~mol}^{-1}$; this stage presents higher activation energy in oxidative atmosphere. It is well known that the carbon-carbon double bond disassociation energy is greater than that of single bond, and thus single bond scission occurs first. ${ }^{9}$

Stages I and II (Fig. 3) clearly gave evidence that in the activation energy of rubber samples, the resistance to thermal degradation decreased with increasing temperature in oxidative atmosphere when compared with step I. The third stage of degradation for sample collected in June, a small increase in the activation energy was observed compared to the second stage. This variation was already expected because when more than one degradation mechanism is occurring, the activation energy will not always be constant. ${ }^{10}$

According to the literature ${ }^{30}$ polymer degradation is a complex phenomenon involving many reactions that are difficult to analyse separately. During the early stages of degradation random scission occurs along the main chains with simultaneous oxidation and crosslinking and therefore becomes an autocatalytic process with the reaction course. As the reaction proceeds, the increasing weight fraction of decomposed sample was observed as well as many concurrent degradation processes such as oxygen uptake, peroxide formation and cross-linking. Besides that the thermal degradation behaviour of NR also depends on the type of rubber Hevea clones as verified by Moreno et $a l^{28}$ and Medeiros et al. $^{30}$

Plasticity retention index $(\%)$ values are presented in Fig. 5. According to the months of collection, it was observed that only the results obtained for clone PR255 met the requirements of the standards ABNT/ NBR11597 (minimum 60\%). ${ }^{4}$ All clones have shown a decrease around $20 \%$ for samples collected in June compared with February. In this set of Hevea samples, it can be seen that PR255 had higher PRI than GT1 clone. According to the literature, ${ }^{32,33}$ PRI variations in NR are influenced by genetic differences among clones and by alterations of climatic conditions that act directly on the synthesis of non-rubber constituents from the latex

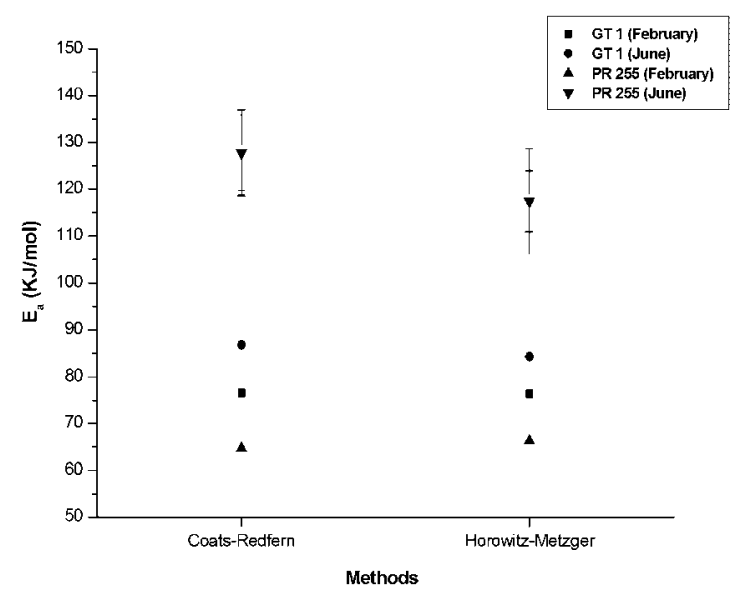

4 Results of activation energy $E_{\mathrm{a}}$ of thermal decomposition curve (in inert atmosphere) for NR samples by different methods

obtained by tappings, mainly tocopherols, presenting a strong antioxidant action.

Since $E_{\text {a }}$ provide measure of the resistance to thermal degradation (a higher $E_{\mathrm{a}}$ indicates a more stable material), it was observed that the values of activation energy ranged between the most and the least thermally stable clones (in the first stage of degradation), i.e. the June samples are the least stable rubbers among the studied ones, whereas February samples exhibited the highest values of activation energy (Fig. 3). Oxygen generally tends to act as an oxidising agent promoting, therefore oxidative degradation, which is more time dependent and more accentuated with increasing temperature than normally occurs for experiments carried out under the nitrogen atmosphere. Actually, for polyisoprene in its solid state, the balance between scission and cross-linking depends on available oxygen diffusing in the material. ${ }^{23}$

Thermogravimetric data provide information on thermal breakdown, mass loss of the material in different stages, threshold temperature, and the nature and the extent of the degradation of the material. ${ }^{25}$ The clones showed similar and different thermal behaviours in inert and oxidative atmospheres respectively. PRI values of the samples have shown variation among the tappings (February and June). Regarding the clonal origin, PR255 clone collected in June had a very higher PRI value compared to GT1 clone collected in June (Fig. 5) and the lower $E_{a}$ (calculated from TG curves) in stage I (Fig. 3), this was probably because the two techniques were not equivalent regarding the phenomenon measured. Therefore, these results also suggest that different conditions, not thermal ones, were mainly responsible for the PRI differences.

\section{Conclusions}

This study indicated that the thermostability of raw rubber samples, from GT1 and PR255 clones, in air is substantially lower than that in nitrogen and the decomposition mechanism is more complex. The decomposition changes from a one stage process to a three stage process, when moving from an inert to an oxidative atmosphere. The activation energy values obtained by Horowitz-Metzger and Coats-Redfern methods were in good agreement with each other. The samples collected in 


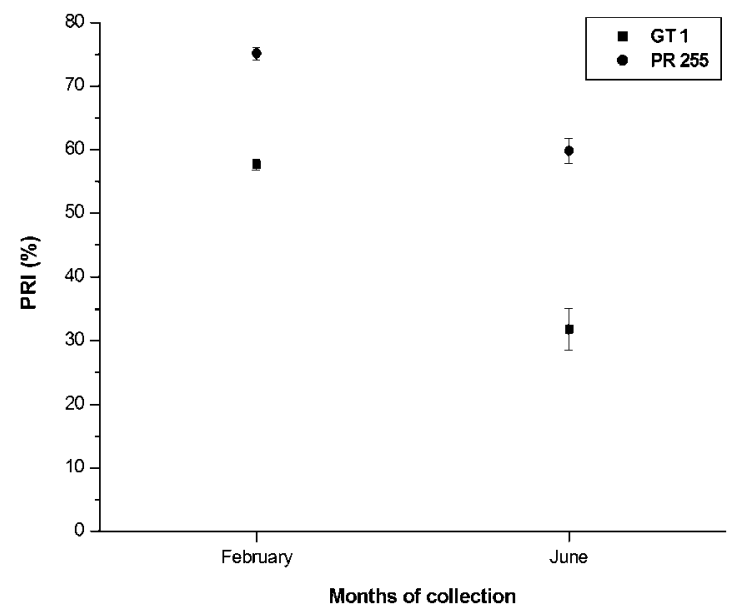

5 Plasticity retention index values of NR samples from GT1 and PR255 clones

June are the least stable rubbers among the studied ones, whereas samples collected in February exhibited the highest values of activation energy and PRI, which indicates that the thermo-oxidative stability of the June samples is the poorest during the thermo-oxidative degradation reaction, and that of the February samples are the best. The composition and chemical structure of raw NR samples change in each pyrolysis stage, due to complicated chemical structure as a result of the interactions of non-rubber compounds, such as proteins and lipids, with the polyisoprene chains. The variations in the thermal behaviour, activation energy $E_{\mathrm{a}}$ and PRI's measures, therefore, were expected because of the genetic differences, intrinsic to each clone type, which are generally reflected in latex and rubber properties.

\section{Acknowledgements}

The authors thank Conselho Nacional de Desenvolvimento Científico e Tecnológico (CNPq) and Fundação de Amparo à Pesquisa do Estado de São Paulo (FAPESP) for their financial support, and Embrapa Agricultural Instrumentation (Brazilian Agricultural Research Corporation) and Plantation Edouard Michelin, Brazil for their institutional support for this study.

\section{References}

1. K. Cornish: Phytochemistry, 2001, 57, 1123-1134.

2. H. Mooibroek and K. Cornish: Appl. Microbiol. Biotechnol., 200, 53, 355-365.

3. R. Morgans, S. Lackovic, B. McGarry, G. Dinnage and B. Pearce: 'Importance of experimental parameters on rapid plasticity testing for PRI (plasticity retention index)', Proc. Int. Rubber Conf., Chennai, India, December 1998, International Rubber Conference Organisation, GAK - Gummi Fasern Kunststoffe, Issue 12, 1999.
4. Associação Brasileira de Normas Técnicas: 'Borracha Natural', Norma NBR 11597; Associação Brasileira de Normas Técnicas, Rio de Janeiro, Brazil, 1996.

5. A. P. Mathew, S. Packirisamy and S. Thomas: Polym. Degrad. Stab., 2001, 72, 423-439.

6. N. Hinchiranan, W. Lertweerasirikun, W. Poonsawad, G. L. Rempel and P. Prasassarakich: J. Appl. Polym. Sci., 2009, 113, 1566-1575.

7. M. N. S. Kumar, Z. Yaakob and X. Siddaramaiah: J. Appl. Polym. Sci., 2009, 114, 467-474.

8. J. M. Salin and J. C. Seferis: J. Appl. Polym. Sci., 1993, 47, 847.

9. P.-T. Liu and X.-G. Jian: High Perform. Polym., 2009, 21, 424- 436.

10. E. S. Medeiros, P. D. Galiani, R. M. B. Moreno, L. H. C. Mattoso and J. A. Malmonge: J. Therm. Anal. Calorim., 2010, 100, 10451050.

11. M. Chen, N.-J. Ao, Y.-Y. Liao, Y. Chen and H.-L. Zhou: J. Appl. Polym. Sci., 2006, 100, 3809-3815.

12. J. Cai and L. Bi: Energy Fuels, 2008, 22, 2172-2174.

13. A. S. Sirqueira and B. G. Soares: J. Appl. Polym. Sci., 2007, 103, 2669-2675.

14. Y.-F. Shih and Y.-C. Chieh: Macromol. Theory Simul., 2007, 16, $101-110$.

15. H.-C. Jun, S. C. Oh, H. P. Lee and H. T. Kim: Korean J. Chem. Eng., 2006, 23, 761-766.

16. B. N. Achar and M. A. Ashok: Chem. Phys., 2008, 108, 8-15.

17. F. Bonfils, J. C. Laigneau, H. Livonnière and J. S. Beuve: Kautsch. Gummi. Kunstst., 1999, 52, 32-36.

18. G. Marinović, M. Marinović-Cincović, V. Vodnik, B. Radovanović, J. Budinski-Simendić and O. Veljković: J. Therm. Anal. Calorim., 2009, 97, 999-1006.

19. L. A. Pérez-Maqueda, P. E. Sánchez-Jiménez and J. M. Criado: Polymer, 2005, 46, 2950-2954.

20. H. H. Horowitz and G. Metzger: Anal. Chem., 1963, 35, 1464 1468.

21. A. W. Coats and J. P. Redfern: Nature, 1964, 20, 68-69.

22. H. Kumar, A. A. Kumar and X. Siddaramaiah: Polym. Degrad. Stab., 2006, 91, 1097-1104.

23. F. Ngolemasango, E. Ehabe, C. Aymard, J. Sainte-Beuve, B. Kouonkam and F. Bonfils: Polym. Int., 2003, 52, 1365-1369.

24. J. Tangpakdee and Y. Tanaka: Rubber Chem. Technol., 1997, 70, 707-713.

25. M. A. Martins, R. M. B. Moreno, C. M. McMahan, J. L. Brichta, P. de S. Gonçalves and L. H. C. Mattoso: Thermochim. Acta, 2008, 474, 62-66.

26. S.-D. Li, Y. Chen, J. Zhou, P.-S. Li, C.-S. Zhu and M.-L. Lin: J. Appl. Polym. Sci., 1998, 67, 2201-2211.

27. A. K. Sircar: J. Therm. Anal., 1997, 49, 293-301.

28. R. M. B. Moreno, E. S. Medeiros, F. C. Ferreira, N. Alves, P. de S. Gonçalves and L. H. C. Mattoso: Plast. Rubber Compos., 2006, 35, $15-21$.

29. S.-D. Li, H.-P. Yu, Z. Peng, C.-S. Zhu and P.-S. Li: J. Appl. Polym. Sci., 2000, 75, 1339-1344.

30. E. S. Medeiros, R. M. B. Moreno, F. C. Ferreira, N. Alves, A. E. Job, P. de S. Gonçalves and L. H. C. Mattoso: Prog. Rubber Plast. Recycl. Technol., 2003, 19, 189-203.

31. L. V. Abad, L. S. Relleve, C. T. Aranilla, A. K. Aliganga, C. M. San Diego and A. M. de la Rosa: Polym. Deg. Stab., 2002, 76, 275 279 .

32. F. Bonfils, A. Doumbia, C. Char and J. S. Beuve: J. Appl. Polym. Sci., 2005, 97, 903-909.

33. R. M. B. Moreno, P. de S. Gonçalves and L. H. C. Mattoso: Kautsch. Gummi. Kunstst., 2008, 10, 528-530. 